\title{
Disinformation and fraud
}

SIR-As one deeply concerned with the nature of information in Western societies, I was distressed at the prejudicial framework in which you presented the Stewart/Feder study (15 January 1987). Although I am not competent to judge the scientific issues, I am qualified to discuss the presentation of information. In that respect, I think you are remiss.

Your leading article and the articles by Stewart/Feder and Braunwald raise the following questions:

How are we to know that the Stewart and Feder work "...is not itself above reproach..." when, as you note, you are not publishing the earlier complete version?

Is not your presentation biased against Stewart and Feder because of the trouble their study and their allegations of scientific fraud have caused you? That is certainly the impression one receives from your description of the tortuous process by which the article was published.

Certainly an editor has the right, if not the duty, to discuss whatever issues he deems fit in an editorial column, but weak sarcasm such as "thanks to the marvellous powers of word-processors..." the use of negative words and phrases such as "tedious details," "injudiciously" as well as "the truth is that the document by Stewart and Feder has now acquired a notoriety comparable with the Darsee affair itself" characterize Stewart and Feder as obnoxious children intent on being heard at all costs.

How, indeed, can those who discuss disinformation be as notorious as those who perpetrate fraud? Are "honest mistakes" and minor discrepancies to be tolerated? One need only consider the Challenger disaster for an answer to that question. Yet the pious tone of your presentation, and that of Braunwald's, obscures the impact of the Stewart/Feder findings by mildly agreeing that they were probably right in some areas but are making too much of it. How can anyone make too much of such errors, inaccuracies and misleading statements in a world poised on the brink of so many disasters?

In particular, Braunwald utilizes intellectual sleight-of-hand to answer accusations with accusations, as on the coauthorship issue. Either he was involved and should have known what was happening or he was not and should not have been a co-author. He cannot have it both ways while denying Stewart and Feder the right to have it either way. To quote Braunwald, "how is the cause of science served by making such unfair accusations?".

Is not your editorial remiss in ignoring the fact that Braunwald, whose comments in response to Stewart/Feder are endorsed in your editorial, was one of Darsee's co- authors? Only by reading Braunwald's commentary does one discover that he is not an objective commentator. Further, nowhere in your issue of 15 January may readers learn that Braunwald's attorney was responsible for a considerable portion of the litigious threats that led to the current abridgment.

One might also wonder about your uncited reference to the New York Times (26 April 1986)... as that edition carries no reference to this case. If your reference is to the Times of 22 April 1986, one might overlook your honest mistake of dates but your phrase "...their ... series of statements..." in no way fairly or accurately reflects Philip Boffey's lengthy and wellbalanced feature article.

Perhaps these items are minor and insignificant. But given the nature of information, it seems incumbent on every publication to present information carefully and without prejudgement.

Neither should one assume, a priori that published information is correct. One need only look at cases such as Darsee's, that of Drs Stalcup and Mellin at the Columbia College of Physicians, Bio-Tech Lab's 208 fraudulent studies, how the scientific community reacted to Immanuel Velikovsky, Derek Freeman's indictment of Margaret Mead's work, the implications of the Broad/Wade book, Betrayers of the Truth, Einbinder's The Myth of the Britannica and to numerous other examples of disinformation to know that our information systems, at best, are pretty tenuous.

At the very least, it seems incumbent upon publications such as yours to approach controversy with the open spirit of the empirical method. Let the data speak and avoid pious, prejudicial characterizations. Unfortunately you have not done so in this case.

32459 Nottingwood,

Dan GreenberG Farmington Hills, Michigan 48018, USA

- Readers must judge for themselves on most of the points raised by Mr Greenberg, but he is mistaken to imply that the original version of the Stewart/Feder article would have been published (at nearly twice the length) had it not been for the intervention of Dr Eugene Braunwald's attorney.

Editors have a duty to potential complainants (as well as to their colleagues, whose salaries may be at stake) not to publish libels. The libellous character of the original version was self-evident, an opinion confirmed by Nature's own legal advisers and, later, by Braunwald's attorney; plainly it is not an easy task to ensure that statements based on inferences from a scrutiny of the scientific literature, and purporting often to describe the state of mind of those concerned, should be capable of substantiation. (In US libel law, defamatory falsehoods are vulnerable; in English law, under which truth is not a sufficient defence, the attribution of malign motives to people is a familiar recipe for aggravating jury damages.)

The chief abbreviation of the Stewart/ Feder manuscript (with the consent of the authors) was the omission of a long and speculative discussion of the reasons why researchers sometimes publish lies and carry co-authors with them in the process; from his personal knowledge of the texts, Greenberg must know that his suspicion that the full text would have been beyond reproach is misplaced.

Many but not all of the later comments on the truncated text offered by Braunwald's attorney were acknowledged by Nature to bear on statements whose veracity could not have been substantiated; on most but not all of these occasions, the authors agreed, not always reluctantly, that their text should be amended accordingly. The value of what Stewart and Feder have done is to draw attention to a serious problem in the organization of research and its reporting in the scientific literature which would not, in the opinion of Nature, have been enhanced it it had been libellous as well. - Editor, Nature.

SIR-Stewart and Feder's investigation of a scientific fraud ( Nature 324, 207; 1986) left me dissatisfied because it did not mention the role of journal editors in publishing fraudulent or inferior material. Clearly the editors are responsible if such material is published. Some of the discrepancies in some of Darsee's publications, for instance, were quite blatant, and should have been noticed by a reviewer. It also seems that the inclusion of a leading figure among the authors helps to get an article published.

I hope the Stewart and Feder article will teach editors the lesson that thorough reviewing is important, and that quality and not authorial prestige should decide what gets published.

Peter P. Heilemann

64-05 155 Street,

Flushing, New York 11367, USA

\section{Unemployment figures}

SiR-On behalf of the Save Science Society, I am making a survey of unemployment among British scientists and would like to hear (in confidence) from those affected, with brief details of professional qualifications, areas of previous study, publications and previous employment.

68 St Albans Road,

BARBARA HALL

Kingston-upon-Thames,

Surrey, KT2 $5 H H, U K$ 